\title{
CHANGES IN THE WHOLE VAGINA OF THE MOUSE DURING ESTRUS AND PREGNANCX
}

\author{
R. DEAN SCHICK \\ Department of Zoology, University of Michigan, Ann Arbor, and Department of \\ Physiology, The Ohio State University, Columbus \\ TEN TEXT FIGURES AND TWWO PLATES (TWELVE FIGURES)
}

\section{INTRODUCTION}

Since the important discoveries by Stockard and Papanicolaou ('17), correlating cyclic changes in the vaginal epithelium with reproductive periodicity, there has been an increasing interest in the physiology of reproduction. The facility with which vaginal smears can be repeated and the multiplicity of ways in which the epithelial cycle can be affected without sacrifice of animals probably explains the preponderance of literature on this subject. Relatively few studies of other vaginal tissues have been made in an effort to correlate changes in the whole birth-canal with reproductive physiology.

Obermüller ('00) reported connective tissue changes in the vaginal wall which were associated with pregnaney and age. Runge ('24) verified these observations of connective tissue enlargement during pregnancy and mentioned epithelial proliferation in the human vagina. The results of his biophysical studies of tissue samples from pregnant women established a corresponding increase in the percentage of water. Stieve ('25) then made the most complete study of human vaginal histology yet undertaken. He reported hyperplasia and enlargement (emphatically not simply swelling) of all tissue layers accompanied by a remarkable loosening of the connective tissue and muscular layers. Stieve's work indicated that the whole vagina changes during pregnancy and 
that it should, therefore, be studied as a unit, a suggestion little heeded.

Hammond (' 35 ) found an increase of $570 \%$ in the weight of the vagina of the pregnant rabbit. Korenchevsky and Hall ('37) reported a $93.5 \%$ increase in the rat's vagina when they compared diestrous weights with those of "late pregnancy." Other studies of vaginal growth have dealt specifically with the epithelium and have been made mostly on non-pregnant animals. For example, Clauberg ('31) compared changes in the vaginal epithelium only, of the pregnant with the nonpregnant mouse. Discussion of these studies would, however, be too lengthy here.

There seems to be no adequate description of changes in the whole vagina of the mouse throughout the reproductive cycle. This study has been undertaken in an attempt to correlate changes in vaginal weight and circumference during the estrous cycle, pseudopregnancy and pregnancy with histological and physiological phenomena occurring at these times.

\section{MATERIALS AND METHODS}

An inbred strain of albino mice of adequate heritage and history was selected for the present study. Laboratory care was uniform except for minor variations in diet and cleaning: routine. The animals selected for study were sexed and segregated at weaning. At 10-16 weeks the virgin females were sorted into uniform age-weight groups. Individuals in these groups varied no more than 1-2 gm. which is a smaller variation than was found in sample litter-mate groups.

Matings for studies of pseudopregnancy and pregnancy were achieved by placing 8-10 females in a box with one or two males. When pseudopregnant animals were desired, the males were vasectomized. Examinations were made each morning for vaginal plugs which indicate a successful mating. If a plug was present, the mouse was numbered by ear-notches and segregated.

Vaginal smears were made with a wire loop and were diagnosed at once. To produce mitotic stasis in dividing cells 
injections of colchicine were made 6 hours previous to sacrifice $(0.025 \mathrm{mg}$. per $20 \mathrm{gm}$. of body-weight). The possibility that colchicine may have a slight mitogenic effect is admitted (Worthington and Allen, '39) but if this factor is kept constant comparative data are still valid.

Animals were killed by disarticulating two cervical vertebrae or by lethal doses of anaesthetics (chloroform or ether). The exposed reproductive organs were first freed of excess fat and mesenteries, then ovaries, oviducts, uteri, and vagina were removed intact by cutting the vagina at its junction with the hair line (Snell, fig. 75, p. 147). The upper limit of the vagina is less well defined, so a recognizable constriction just above the cervix was chosen for convenience and consistency in dissection. After removing the bladder by cutting the urethra at its base, the vagina was placed in a small glass vial which was then stoppered and weighed. Dry weights were taken after desiccation (temperature $105^{\circ}-110^{\circ} \mathrm{C}$.) until no further water-loss was detectable. Freshly excised vaginas were fixed immediately after weighing in Bouin's fluid. Embedding was in paraffin. Sections were cut from the center of the vagina at 10 micra. Mallory's triple stain was used together with hematoxylin for histological differentiation as well as nuclear detail. Other sections were stained with Harris' hematoxylin and eosin or with Verhoff's elastic tissue stain.

Measurements of vaginal circumference were made on projected images, magnified $160 \times$. A map-measurer was run around the external margin for the perimeter, and around the basal layer of epithelial cells for a mucosal circumference. The circumference-value for any individual is the mean of at least three readings. Group-values represent averages of these mean readings.

Mitotic counts were based on the number of metaphase figures as compared to the number of interphasic nuclei in any one tissue-layer of a field chosen at random. These were calculated as percentage of mitoses per tissue-layer per field, and the mean of at least three fields for each section was 
determined. The percentage of mitotic figures for each vagina was then calculated by averaging the mean percentages of each section counted. To eliminate a possible diurnal variable in mitotic frequency, mice were sacrificed at approximately the same time of day (mid-afternoon). Nuclear measurements were made by means of a filar ocular micrometer. Only the contrasting groups of diestrus and late pregnancy were compared. Four of the largest recognizable nuclei of each vaginal tissue-layer were measured for six animals in each group as a preliminary study. Further analysis did not seem to be essential.

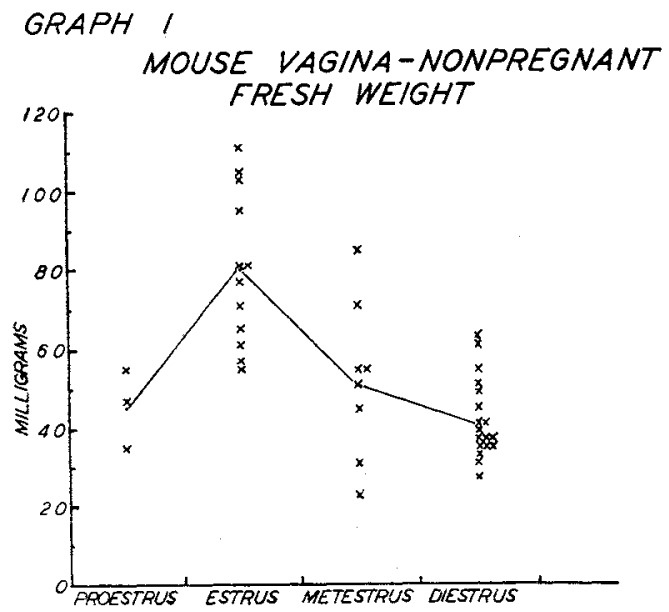

RESULTS

Estrous changes in the vagina

Periodic growth in the vagina is associated with phases of the estrous cycle. There is an increase in weight during proestrus reaching a maximum of $95 \%$ at estrus, a decline corresponding to the metestrous sloughing of the superficial layers, and a diestrous minimum. Thus the mean-weight curve for such a series of vaginas correlates with the vaginal smear history (graph I). Since proestrus and metestrus are transitional stages in epithelial growth and degeneration little significance can be attached to the values for these stages 
except that they are intermediate between the estrous and diestrous extremes.

The corresponding circumferential measurements indicate that epithelial proliferation and cornification are also reflected in these values (graph II). Circumference and weightmeasurements are not always in proportion, as is shown by the three proestrous mucosal circumferences which were relatively higher than corresponding means of estrus, while the weights of the same vaginas were lower in proestrus than in

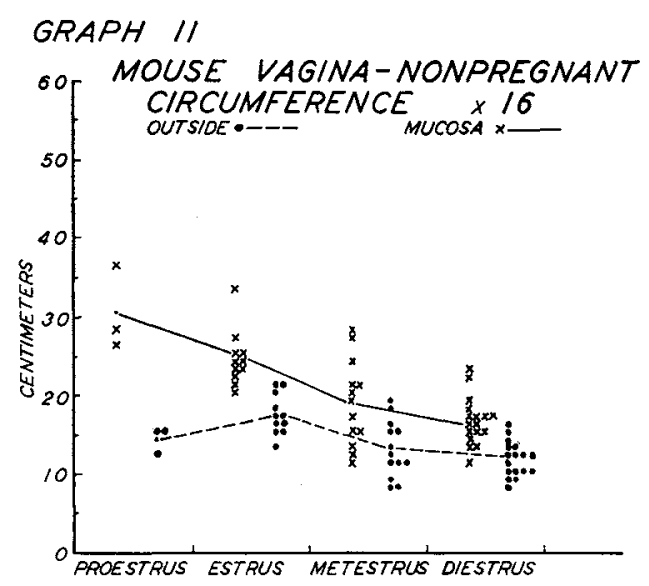

estrus. Considering the estrous and diestrous means as more valid then, the increase in mucosal circumference is $46 \%$ and in perimeter $42 \%$ (graph VIII).

The epithelium of late or prolonged diestrus and of proestrus undergoes a structural change which characterizes it as a true mucosa. The superficial mucification of prolonged diestrus (fig. 8) resembles more closely the development seen in pseudopregnancy and may be considered to result from the same cause: viz. progestin produced by functional corpora lutea. Korenchevsky and Hall ('37) found it "more especially during" winter months" in rats, and regarded it as a "progestation-like feature." Proestrous mucification, however, cannot be so designated. The cells resemble mucous cells, but are usually smaller, less hyaline and are accompanied by an under- 
lying cornified layer. In the rat, Korenchevsky and Hall (op. cit.) failed to secure a typical mucous reaction for the proestrous metaplasia, using Mayer's mucicarmine stain and, therefore, refer to it as "pseudomucous." Otherwise, these types of secretory development have not been distinguished in the literature.

Dividing cells are rarely found, even following colchicine treatment, in any layers of the non-pregnant vagina except those of the epithelium. Cells of the basal layers of the epithelium occasionally show mitotic figures, which are most abundant in proestrus sections and continue to be numerous until late estrus (fig. 7) when there is a wane in their frequency. The fact that mitotic figures are found underneath the firm stratum corneum of estrus is significant in explaining the estrous increment in vaginal circumferences.

The nuclei of the active, growing cells of the epithelial layers are larger and more granular than those of the muscular and connective tissue layers (figs. 7, 10). Occasional large, granular fibroblast nuclei are to be seen both in the lamina propria and in the adventitia. Leucocytes and phagocytes are numerous, especially just before and during diestrus, when they invade the epithelium in large numbers.

\section{Changes of pseudopregnancy and early pregnancy}

Copulation occurs at estrus. It is followed by an interruption of cyclic growth in the vaginal epithelium regardless of whether the male involved is sterile or fertile. Vaginal weight and circumference fall to a minimum 2 or 3 days after copulation, accompanying desquamation, then rise slowly with epithelial proliferation and the characteristic mucification. Vaginas taken from mice after a sterile copulation seem to have heavier mean weights than those of early pregnancy, but these pseudopregnancy-means approach early pregnancymeans in those groups for which larger numbers of animals were weighed (graphs III and V). The circumferential means for both groups are essentially the same (graphs IV and VI). 
Changes in weight and circumference during these periods represent an increment of less than $30 \%$, spread over 8-11 days as a gradual rise, subject to considerable individual variation.

The mucification of pseudopregnancy and early pregnancy, as already mentioned, resembles that of prolonged diestrus.
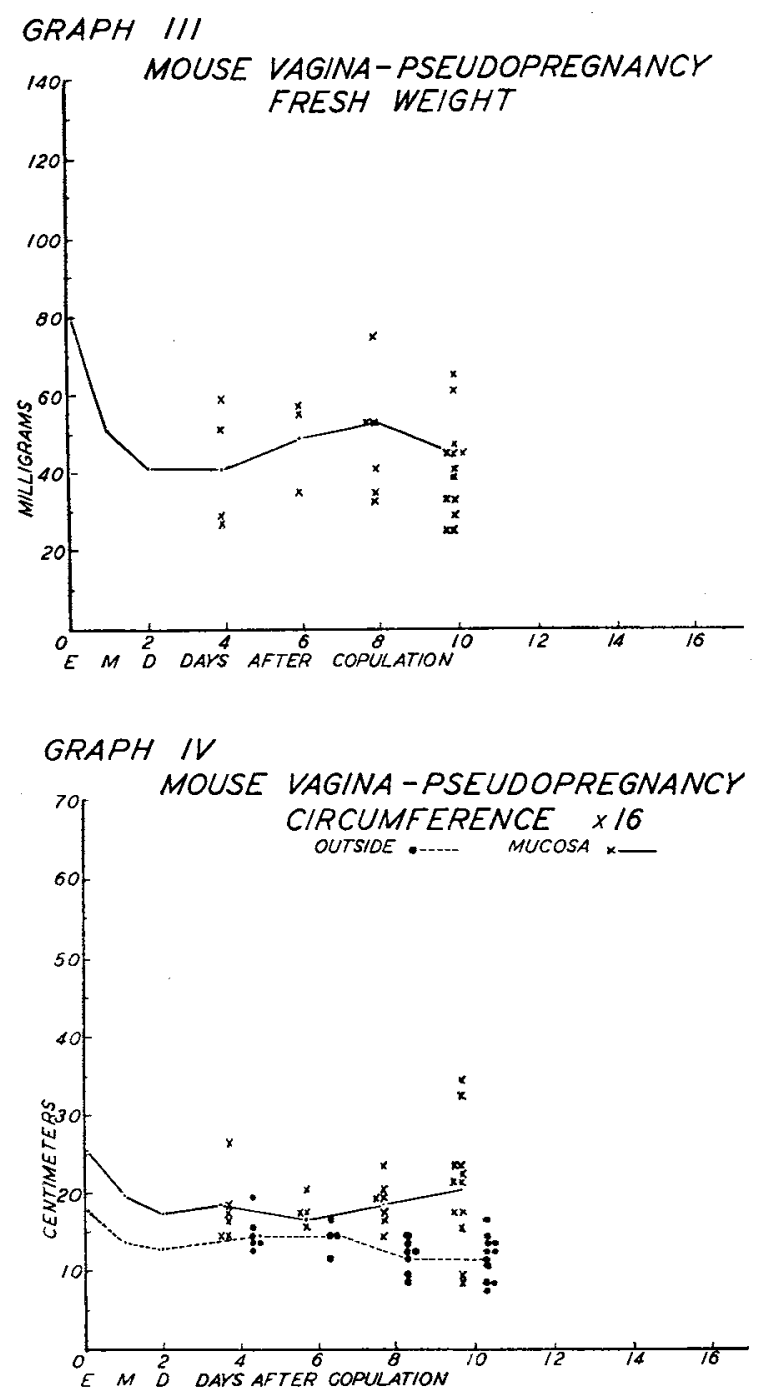
At the end of pseudopregnancy these epithelial layers disintegrate because of proliferation and cornification below. In true pregnancy the process of mucification continues, in the absence of cornification, as the circumference increases and the epithelium becomes more deeply folded.

The incidence of mitotic figures is not significantly changed by copulation (graph IX). Since percentage counts remain relatively constant it is evident that the rate of cellular division keeps abreast of any increase in the number of cells. Only toward the end of pseudopregnancy or mid-pregnancy is an increased mitotic rate noticeable, and this occurs in all layers of the vagina (figs. 10, 11).

\section{Changes of late pregnancy}

The first changes in the vagina which are the direct result of gestation appear 10-12 days after copulation. There is at this time a marked gain in weight and circumference which continues until parturition. Since parturition may oceur at any time between the eighteenth and twentieth days of gestation, vaginas taken at delivery and within a few hours of delivery were averaged together for a parturition-mean. The values for this stage are plotted on an arbitrary ordinate labeled "HRS" on the graphs. Other data from vaginas examined on the first and fourth days following delivery were plotted and labeled accordingly. The increase in weight is apparently more constant than that in the mucosal circumference, reaching its peak at, or within a few hours of, delivery (graphs V, VI, VIII). The vaginal perimeter is also increased until delivery, but the mean mucosal circumference is lower at delivery than before. This fact depreciates the possible effect of stretching on vaginal circumference and suggests the importance of tonus changes in the vaginal wall.

Vaginas from another series of pregnant mice were desiccated, to determine whether the increase in weight represented an increase in tissue-fluids, as Runge ('24) found to be true 

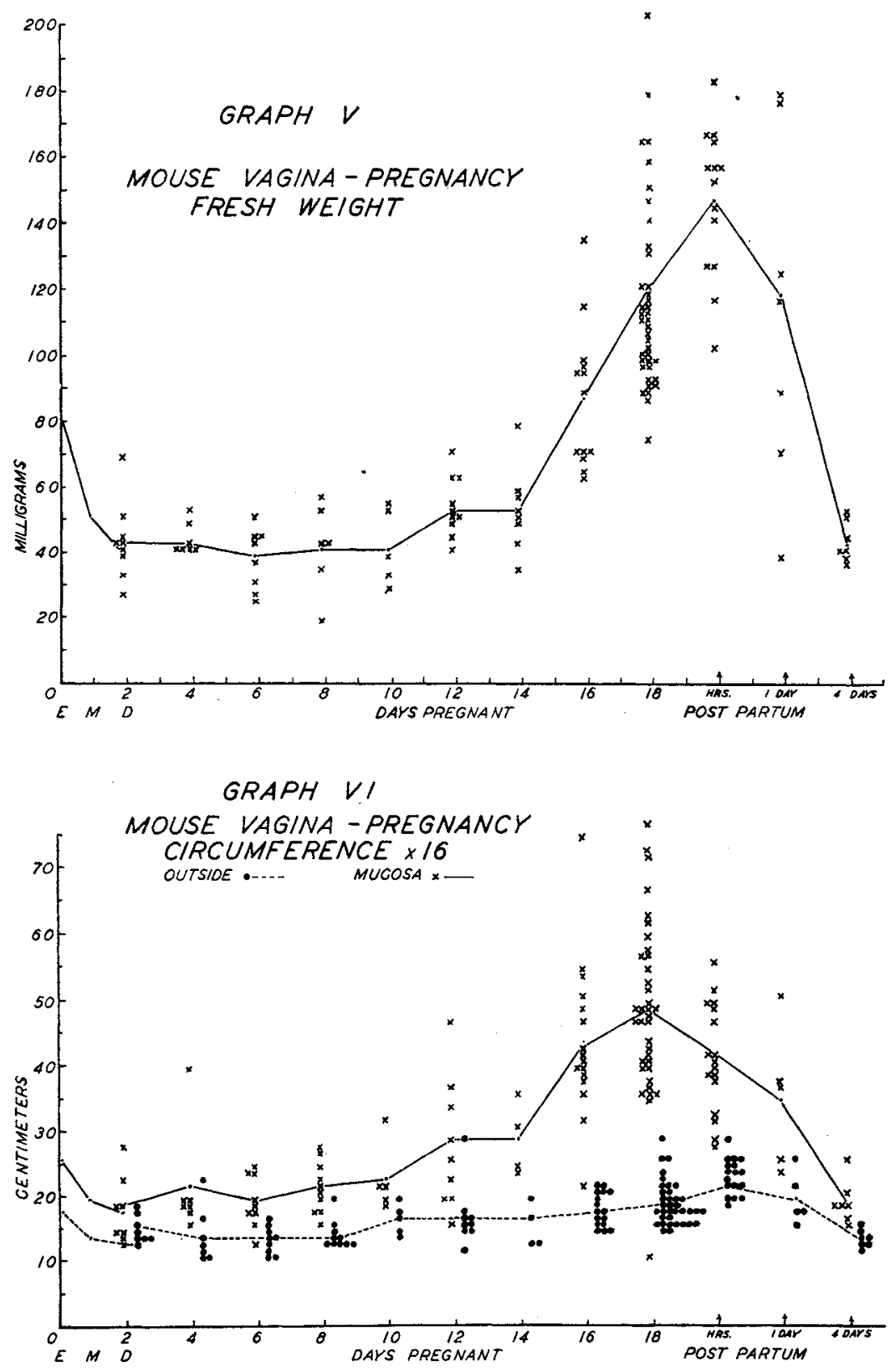
in the human vagina. The mean curve for these data (graph VII) indicates a water content fuctuating near $75 \%$ until mid-pregnancy. The small change in percentage of water is emphasized by graph VIII. Late pregnancy appears to bring
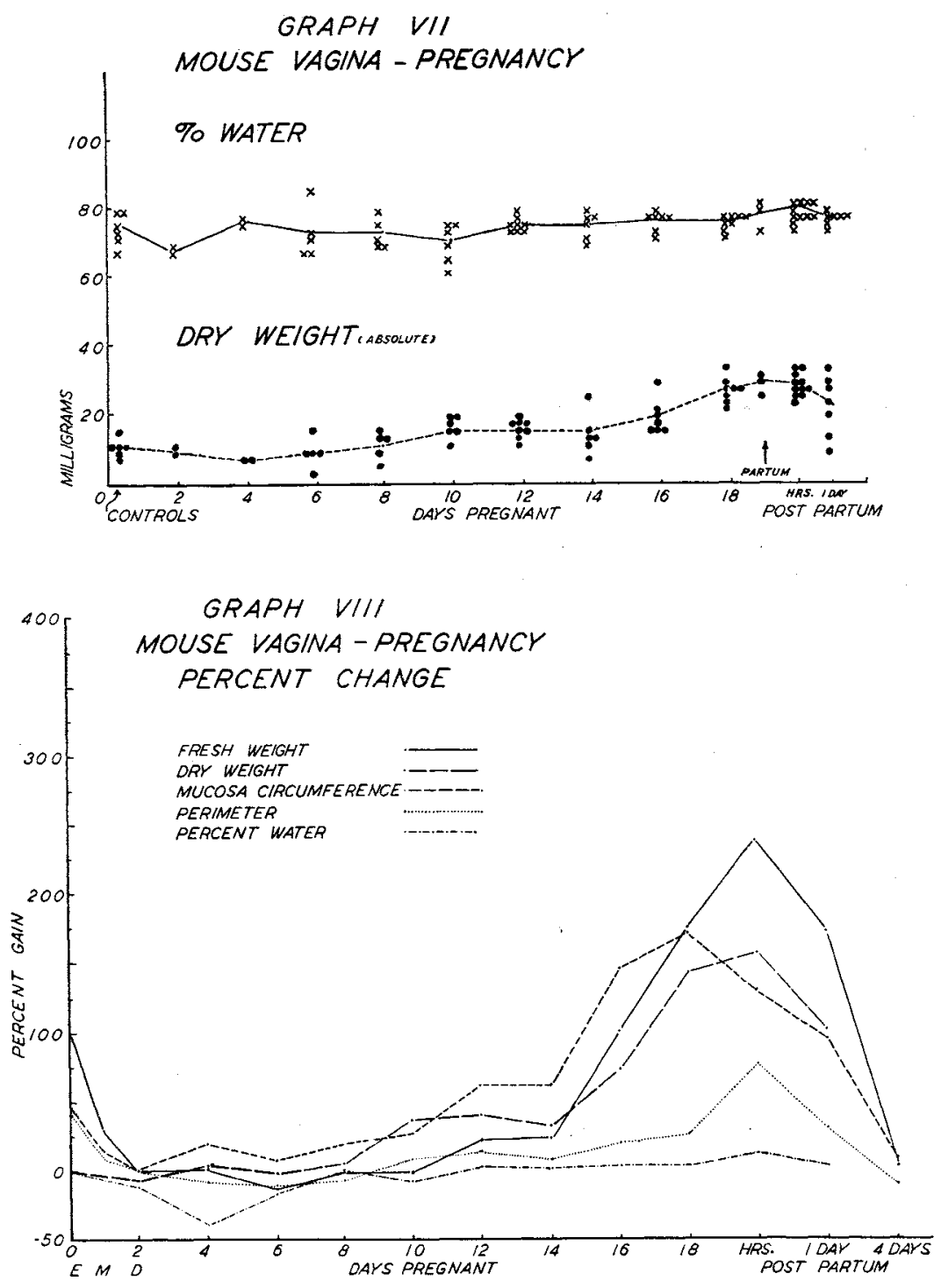
about a rather constant rise in tissue fluid. An $80 \%$ maximum occurs coincident with, or soon after, delivery. Of three animals sacrificed in the act of parturition (tissue water mean $=$ $81.8 \%$ ), one had a vaginal water content equivalent to early pregnancy while the other two had much higher values. All of these animals had very soft cervical canals in contrast with animals sacrificed much before or after delivery. Tissue water is lost rapidly after parturition, a fact which has been associated in the uterus with the removal of placental tissue (Newton, '35; Brooksby and Newton, '38).

In the present study no quantitative relationship could be established between numbers of embryos (placentas) and percentage of water in vaginal tissue. Of the three mice sacrificed during parturition, the one having the lowest percentage of tissue water had eleven embryos, while the other two, with more tissue water, had six and eight embryos respectively.

The absolute dry weights of vaginas (graph VII, VIII) also indicate that the weight gained by the vagina during pregnancy is indeed largely due to the addition of new protoplasm, and that the change in tissue water is only a secondary factor. Histological studies of the prepared sections indicate a loosening of the extra-epithelial tissues to accommodate excess tissue water (figs. 11, 12). There is also evidence of increased vascularization of the vagina. But histological studies give even greater credence to the contention that increased vaginal weight is predominantly due to hypertrophy and hyperplasia.

An increased rate of cellular growth and multiplication is indicated by a slightly greater number of mitotic figures occurring simultaneously in all layers of the vagina during late pregnancy. This increase is exaggerated if one merely counts simultaneous mitotic figures around the vaginal section, not taking into account the increased number of cells actually present. That there is an actual increase is indicated by comparison of the percentage of cells in mitosis and those in interphase (graph IX - standard errors are shown as vertical lines through the means). 
Stieve ('25) presented evidence that cells of all vaginal tissue layers in women undergo hypertrophy during pregnancy as indicated by an increment in nuclear dimensions. Studies of vaginal sections from contrasting groups of mice agree with his findings to this extent, that although the largest nuclei of late pregnancy are no larger than the largest ones of a virgin animal, there are certainly a greater number of large nuclei present in all tissues of the pregnant animal's vagina. This enlargement is particularly noticeable in fibroblast nuclei, which are much less compact and more granular in late pregnancy than earlier.

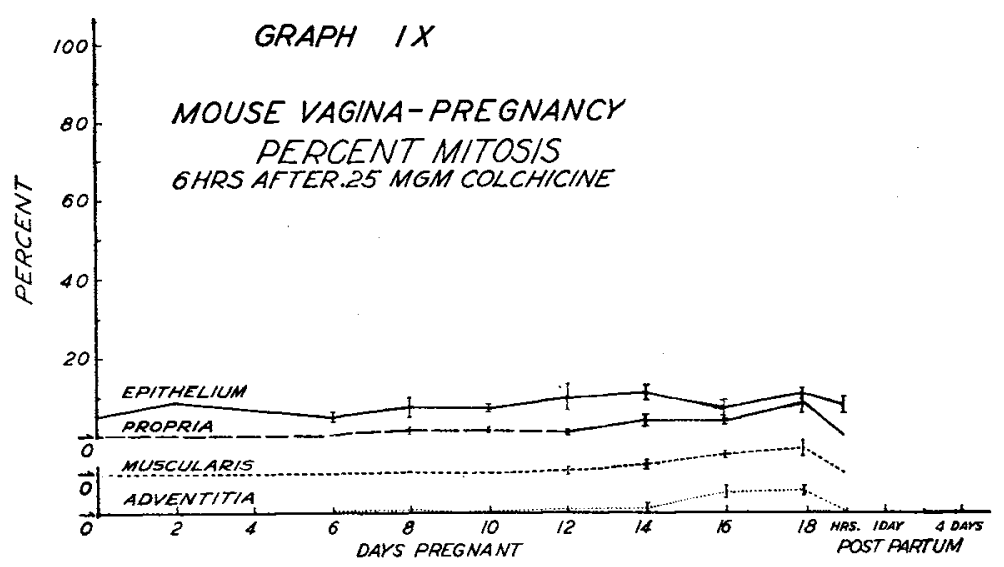

An increase in total body, weight during pregnancy is to be expected because of the increase in the size of the reproductive organs to accommodate the growing embryos as well as the weight of the embryos themselves. It seemed of interest to determine whether there is also an increment in somatic bodyweight with embryos and reproductive organs removed. Such a gain might even be greater in primiparous animals. Under these circumstances changes in body weight during pregnancy are not very striking (graph $X$ ). There is an apparent initial tendency to rise with a fluctuation above and below $28-29 \mathrm{gm}$. for the duration of gestation. The greatest increase in weight indicated by any group is $29 \%$ on the twelfth day of pregnancy. 
The average gain of all groups is $17.4 \%$. Vaginal weight, for comparison, had increased $240 \%$ at its maximum (parturition).
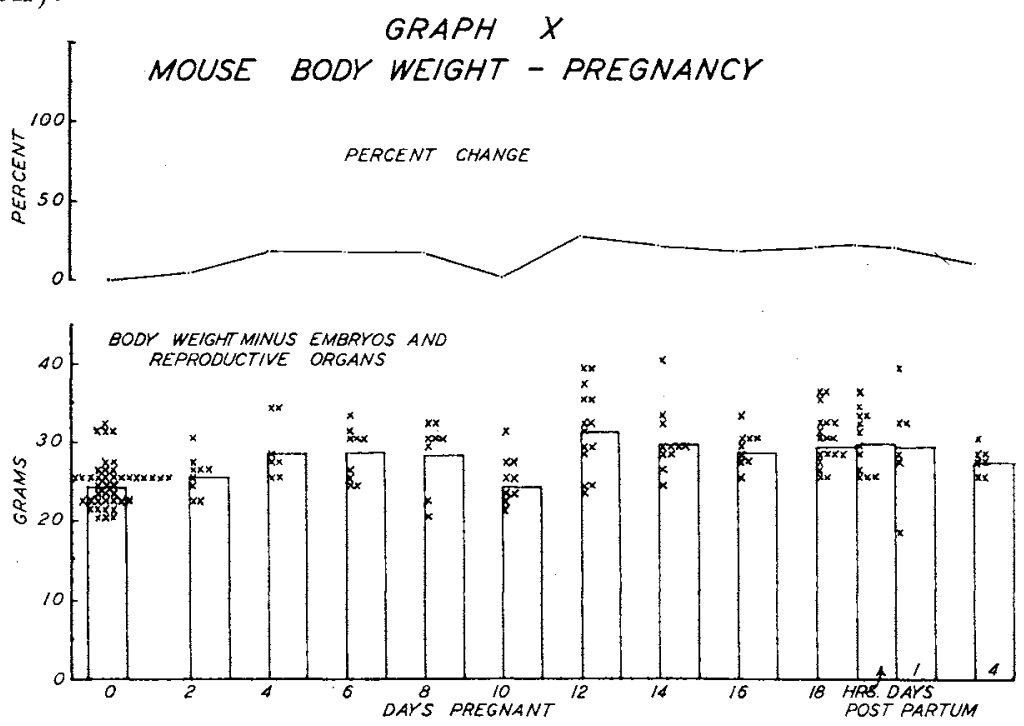

DISCUSSION

Mechanical factors affecting estrous vaginal changes

Estrous changes in vaginal weight and circumference can be explained on the basis of cyclic variations in the superficial epithelium. The increase in weight is due primarily to the proliferation and sloughing of many layers of cornified epithelium supplemented by an increase in tissue fluid due to congestion. Hyperemia of the genitals has long been recognized as an indication of heat in mammals, although it is not particularly marked in mice. Growth and stretching incidental to these factors are sufficient to explain estrous changes in vaginal circumference.

Some folding of the epithelium occurs as proliferation and keratinization progress. Toward the peak of cornification, when the horny layer is several cells thick, lateral pressure is not relieved so readily by folding and the whole section retains its natural symmetry (cf. figs. 1,2). Continued proliferation 
from below, together with hyperemia, would result in a tendency to stretch the muscular and connective tissue layers. Mitosis is common beneath the heavily cornified epithelium of estrus — see figure 7 (also Allen, '22; Clauberg, '31; Snell, '41). The circular muscular layer responds to the increased tension by contraction, increasing tonus and somewhat reducing the vaginal perimeter. In opposition, proliferation tends to increase the vaginal perimeter. Tension is released by desquamation reducing both tonus and circumference, and resulting in the limp, flaccid organ of late diestrus and early proestrus (fig. 2). Except when accompanied or followed by an underlying cornified layer, as during late proestrus, mucification of the superficial epithelial layers allows free folding in response to growth pressure even though many of the superficial cells are turgid with secretion. The vaginal wall remains soft and flexible in pseudopregnancy and early pregnancy, but there is little folding or change in mucosal circumference because proliferation is predominantly epithelial, and vertical or radial in direction (cf. fig. 3 and 4 with fig. 5).

\section{Division of pregnancy into two natural stages}

Pregnancy changes in the vagina of the mouse may be conveniently divided into two stages of approximately equal duration, early and late. Early gestational changes include those transformations in the tissues which occur before mid: pregnancy, chiefly proliferation and mucification of the epithelium (figs. 9, 10). These involve little change in weight or circumference of the vagina (graphs $V, V I$ ), and are not really gestational at all. They occur as a result of copulation and nervous stimulation of the anterior pituitary gland, which then stimulates the formation of more active corpora lutea (Allen et al., '39). The interaction of progestin and estrogen maintains mucification and stimulates radial proliferation.

Beyond mid-pregnancy, changes are more rapid, more pronounced. There is a definite gain in weight and circumference until parturition terminates gestation, then both drop off rapidly within 24 hours as the elaborate mucosa degenerates 
and the blood vessels contract. These changes, occurring between mid-pregnancy and parturition, may be referred to as late gestational changes. Continued mucification and proliferation of the vaginal epithelium is a conspicuous characteristic. The marked increase in mucosal circumference indicates a $90^{\circ}$ change in the direction of predominant mitosis (to lateral or tangential). This interpretation is supported by a continued high rate of mitosis without any increase in the thickness of the epithelium. An increased folding of the mucosa results (figs. 5, 6).

In late pregnancy there is also an inereased rate of cellular division in the connective tissue and muscular layers of the vagina. Vascular elements and tissue spaces are more in evidence (figs. 11, 12) as in the human vagina (Stieve, '25), giving a loose, relaxed appearance to the vaginal wall. These changes in the outer layers contribute to an increased perimeter, but the tissues themselves are still under enough tonus to encourage epithelial folding rather than a stretching of the extra-epithelial layers (fig. 5).

Changes of late pregnancy are distinctly gestational changes, but still depend on the maintenance of functional corpora lutea (or the injection of a progestin-like substitute). Although some mammals can successfuly conclude pregnancy without ovarian progestin (primates, mares, guinea-pigs: cf. Allen et al., '39) apparently because of large amounts of placental hormone, mice cannot (Harris, '27; Parkes, '28). Further, the relative unimportance of the pituitary is emphasized by the observation of Newton and Beck ('39), that in mice the ovaries are more essential to pregnancy than the pituitary, once placentas are established.

\section{Factors influencing vaginal growth indirectly}

Among the factors which might influence general body weight and, therefore, vaginal weight indirectly are (1) natural growth, and (2) growth concomitant with pregnancy, under the stimulation of reproductive or specific growth hormones. 
Correlation between body weight and vaginal weight is high in the non-pregnant mouse, as might be expected. Heavy animals tend to have heavier vaginas, although individual variation is considerable. After reaching puberty at 7-10 weeks, gains in body weight in mice are relatively slow. A mouse of 16-20 weeks gains only a fraction of a gram in 2 weeks (Robertson, '16). It has also been observed by careful metabolic determinations that mice may undergo as much as 6-12\% rise in weight purely as a result of feeding (Brooksby and Newton, '38). Individual differences in absolute body-weight gain plus individual differences in feeding and elimination contribute a considerable discrepancy in body-weight determinations of mice, even though weighings are done consistently and systematically.

The significance of vaginal growth is emphasized above by the demonstration that it is not merely a reflection of increased body weight during pregnancy. The increase in general body weight at this time was not found to be as striking as one might be led to believe from some reports. Cole and Hart ('38) state that pregnancy causes a general growth of tissue in the rat, accompanied by, and presumably dependent on, an increased consumption of food from the second day of conception. Later, Hart and Cole ('39) announced similar gains in response to pseudopregnancy, "less pronounced, however, on account of the absence of embryos.' Brooksby and Newton ('38) found no difference in metabolic rate per gram of body weight in mice during pregnancy, but noted a gain in weight which could not be accounted for by the weight of the uterine contents. They concluded the extra weight was due to an excess of water since it was lost at delivery.

Finally, there is some evidence that ovarian hormones affect general body growth, and thus might affect vaginal growth indirectly as well as directly. Freudenberger and Clausen ('37) found that the continued injection of theelin (200 I.U./2 days) suppressed general body growth of 3-weekold rats in 9 weeks. Ovaries and uteri were considerably larger. The effect on other organs was variable. Billeter ('37), 
using theelin in sesame oil at varying dosages and intervals, noted an increased body weight in rats, chiefly due to fat.

It seems unlikely, from the evidence examined, that general body growth in the mouse during pregnancy affects vaginal growth to a very appreciable extent. Further, the selection of age-weight groups of mice on the basis of a difference in age of not over 4-5 weeks and a difference in weight of $2-3 \mathrm{gm}$. is probably accurate enough to give fairly comparable results in this study.

\section{Factors infuencing vaginal growth directly}

Factors which might influence vaginal weight directly may be summarized under two general headings, (1) factors leading to an increase in dry weight, and (2) factors leading to a disproportionate increase in water.

Increased dry weight involves an increase in protoplasm, either through an enlargement or an increase in the number of cells. Stieve ('25) presents data indicating larger nuclei in cells of all layers of the human vagina during pregnancy. He also measured epithelial cells directly and found them to be larger in pregnancy. Cellular hypertrophy is admittedly less well demonstrated in the present study than are other features. The fact that selected, large nuclei of late pregnancy were no larger than the largest nuclei of any tissue layer of the non-pregnant (diestrous) vagina would indicate that hypertrophy does not occur beyond certain limits in any case (figs. 8, 12). It seemed undesirable to spend the requisite time in measuring all nuclei of each layer for a more exact mean when it was so obvious that relative numbers of enlarged nuclei in vaginal sections increased in late pregnancy. Also, inasmuch as many nuclei would not be cut in their largest diameters, the ranges and deviations of a more complete determination would be highly unreliable, as Stieve must have realized.

An increase in the number of cells does not necessarily imply an increased rate of division. Numbers of cells would be increased if the mortality rate were decreased, or an increased 
cellular life-span might also result in more offspring by an extended reproductive period without any change in the rate of division. A change in the direction of proliferation from radial to tangential could increase cellular number effectively without pushing overlying layers away from their metabolic resources.

Since methods of judging mitotic rate by counting mitotic figures in fixed tissue is subject to considerable error, it was decided that calculations on a percentage basis would be a better index to a change in rate of mitosis in vaginal tissues. In counting interphasic nuclei, all recognizable nuclei of a particular tissue were considered, regardless of size. In the epithelium this would still lead to some error because only the lower layers (S. germinativum) divide (figs. 7, 10, 11). Varying pressures of overlying layers might also influence the direction of division. These factors would tend to lower the actual mitotic rate, even though there were a very real increase as cells accumulate in both directions. Although little increase in the rate of mitosis was determined in the epithelium during pregnancy by this method, actually there is probably more of an increase. Mitotic figures are numerous in the basal layers (figs. 10, 11, 12). Percentage-counts for the lamina propria and muscularis, although the figures are more difficult to recognize, show a certain increase in division-rate and smaller deviations (graph IX).

There are several observations sufficient to accommodate a $5-10 \%$ increase in tissue fluid in the vagina of the mouse during late gestation. First, the engorged mucosal cells are evidence of an increase and storage of fluid. There is a distinct and decided loosening of the tissue of the lamina propria, with clear interstices (fig. 12). This loosening also extends through the muscular layer, occasionally emphasizing the individual fibers of the $M$. longitudinalis. An increased number of blood vessels is apparent, although one could not be certain whether this was due to an enlargement of vessels already in the tissues or to new vascularization. These subjective $o b-$ servations are difficult to qualify at first, but can be recognized 
more certainly with repeated comparisons. The continued rise in fresh vaginal weight a few hours after parturition, followed by a very rapid loss of weight, is evidence in favor of a change in water-content during pregnancy and at its conclusion. This evidence is supported by graphic data (graphs VIII, IX).

Runge's observations on human vaginal tissue ('24, '25) and those of Newton ('35), Brooksby and Newton ('38) on the "water of uterine contents" in the mouse, significantly favor osmotic changes and increased tissue water in late pregnancy. The supplementary observations of Astwood ('38) concerning increased percentage of water in the immature rat's uterus in response to estrogens, support the less well controlled observations of Khayyal and Scott ('34) on the mouse's uterus during estrus - David ('31) and Frank ('29) to the contrary. Since atropine inhibits the cornifying effect of estrogens on the vagina, and since yohimbine simulates these effects (Hechter, Lev, and Soskin, '40) then the estrogenic effect may be due to hyperemia, and tissue water may be controlled by estrogens indirectly in the same way.

The same factors which influence vaginal weight directly would also influence the perimeter and mucosal circumference. Growth, either through an enlargement of, or an increase in the number of, cells is reflected by the circumference, as is a swelling or shrinkage of the cells or tissues. Changes in turgidity or tonus involving a majority of the cells would be indicated in adjustments of circumference, at least temporarily.

Finally, it is to be emphasized that although the changes in the vaginal epithelium are the more spectacular and have been more extensively studied, the changes in the underlying layers are equally important. No matter how elaborate and well lubricated the epithelium, if the muscular and connective tissue layers are not sufficiently stimulated and prepared for delivery the raginal lumen is still small even though somewhat elastic. In such a case an elaborate epithelium would be an impediment to parturition. Stimulated proliferation of the muscular and connective tissue offers decidedly more facilitation in the 
absence of epithelial proliferation than would be offered by a stimulated epithelium in the reversed instance. Even though relatively less elaborate, changes in the outer layers of the vagina are of great significance in its function as a birth-canal.

\section{SUMMARY}

1. Changes in the pregnant vagina of the white mouse may be conveniently divided into (1) early gestational changes and (2) late gestational changes. These stages are of approximately equal duration.

2. Early gestational changes are provoked by copulation, whether fertile or sterile. They occur in pseudopregnancy and true pregnancy alike.

3. Early gestational changes in vaginal histology involve (a) proliferation of epithelial cells, predominantly in a vertical (radial) plane, and (b) mucification of the epithelium.

4. Late pregnancy changes in the whole vagina include (a) a $238 \%$ increase in fresh weight, (b) a $158 \%$ increase in dry weight, (c) a $5-10 \%$ increase in water, (d) a $172 \%$ increase in mucosal circumference, and (e) a $50 \%$ increase in perimeter.

5 . There is an average gain of only $17.4 \%$ in general bodyweight of the mouse during pregnancy, when the weights of the reproductive organs and embryos are not included.

6. Late pregnancy changes in vaginal histology involve (a) maintenance of mucification, (b) increased proliferation of epithelial cells, predominantly in a horizontal (tangential) plane, (c) an increased rate of division in connective tissue (lamina propria) and smooth muscle cells, (d) an increase in inter-cellular spaces providing a loosened appearance in connective tissue and muscular layers, and (e) an increased vascularization of the vaginal wall.

7. Late pregnancy changes in the vagina as a whole can be satisfactorily explained on the basis of concomitant histological changes.

\section{ACKNOWLEDGMENT}

The author is particularly grateful to Dr. Alvalyn E. Woodward, of the University of Michigan, under whose direction this problem was pursued. The photographs were furnished 
by the Department of Physiology, Ohio State University, where certain phases of the work were completed. Experimental and statistical data are on file at the General Library of the University of Michigan.

\section{LITERATURE CITED}

AlleN, E. 1922 The oestrus cycle in the mouse. Am. J. Anat., vol. 30, pp. $297-348$.

Allen, E., C. H. Danforth and E. A. Doisy (Edrors) 1939 Sex and Internal Secretions. Williams \& Wilkins, Baltimore.

ASTwood, E. B. 1938 A six-hour assay for the quantitative determination of estrogen. Endocrinology, vol. 23, pp. 25-31.

Billeter, O. A. 1937 The effect of spaying and theelin injections on body growth and organ weights of the albino rat. Am. J. Anat., vol. 60, pp. 367-395.

BrooksBy, J. B., AND W. H. NEWTON 1938 The effect of the placenta on the body weight of the mouse. J. Physiol., vol. 92, pp. 136-150.

Clauberg, C. 1931 Genitalcyclus und Schwangerschaft bei der weissen Maus. (Anatomische Studien an Ovarium, Uterus, und Scheide.) Dauer des Genitalcyelus. Arch. f. Gynäk., vol. 147, pp. 549-596.

Cole, H. H., AND G. H. HART 1938 Effect of pregnancy on growth in the rat. Am. J. Physiol., vol. 123, pp. 589-597.

DAVID, J.C. 1931 The action of oestrin on the oxygen consumption of the uteri of mice. J. Pharmacol. \& Exper. Therap., vol. 43, pp. 1-11.

Frank, R. T. 1929 The Female Sex Hormone. Thomas, Baltimore.

FreUdenBerger, C. B., AND F. W. Clausen 1937 The effect of continued theelin injections on the body growth and organ weights of young female rats. Anat. Ree., vol. 68, pp. 133-144.

HAMMOND, J. 1935 The changes in the reproductive organs of the rabbit during pregnaney. Trans. on Dynamies of Development, vol. 10, p. 109.

HaRRIS, R. G. 1927 Effect of bilateral ovariectomy, upon the duration of pregnancy in mice. Anat. Rec., vol. 37, pp. 83-92.

HART, G. H., AND H. H. CoLE 1939 Cause of increased growth during pseudopregnancy. Proc. Soc. Expr. Biol. and Med., vol. 41, pp. 310-313.

Hechter, O., M. LeV AND S. Soskin 1940 The relation of hyperemia to the action of estrin. Endocrinology, vol. 26, pp. 73-79.

Khayyal, M. A., And C. M. Scotr 1934 The oxygen consumption of the isolated uterus of the rat and mouse. Quart. J. Exper. Physiol., vol. 24, pp. $249-259$.

KORENCHEVSKY, V., AND K. HALL 1937 The bisexual and cooperative properties of the sex hormones as shown by the histological investigation of the sex organs of female rats treated with these hormones. J. Path. \& Bact., vol. 45 , pp. $681-708$.

Newton, W. H. 1935 "Pseudoparturition" in the mouse, and the relation of the placenta to post-partum oestrus. J. Physiol., vol. 84, pp. 196-207.

Newton, W. H., AND N. BECK 1939 Placental activity in the mouse in the absence of pituitary gland. I. Endoerinol., rol. 1, pp. 65-75. 
ObermüLLer, K. 1900 Untersuchungen über das elastische Gewebe der Scheide. Beitr. z. path. Anat. u. z. allg. Path., vol. 27, pp. 586-590.

PARKES, A. S. 1928 The role of the corpus luteum in the maintenance of pregnancy. J. Physiol., vol. 65, pp. 341-349.

ROBERTSON, T. B. 1916 Experimental studies on growth. II. The normal growth of the white mouse. J. Biol. Chem., vol. 24, pp. 363-383.

Runge, H. 1924 Die plastische Geburtsdehnung der Vagina. Areh. Gynäk., vol. 122 , pp. 603-631.

RungR, H., AND R. KEssleR 1925 Beitrag zur Physiologie des Wasserstoffwechsels in der Schwangersehaft. Arch. Gynäk., vol. 126, pp. 45-64.

SNelL, G. D. (Ed.) 1941 Biology of the Laboratory Mouse. Roseoe B. Jackson Memorial Laboratory Staff. Blakiston, Philadelphia.

STIEvE, H. 1925 Das Sehwangerschaftswachstum und die Geburtserweiterung der menschlicher Scheide. Ztschr. f. mikr.-anat. Forsch., vol. 3, pp. 307-366.

STOCKARD, C. R., AND G. N. PAPANicolaou 1917 The existence of a typical estrous cycle in the guinea pig with a study of its histological and physiological changes. Am. J. Anat., vol. 22, pp. 225-265.

Worthington, R. V., AND E. Allen 1939 Growth of genital tissue in response to estrone as studied by colchicine technic. Yale J. Biol. \& Med., vol. 12, pp. 137-153.

\section{PLATE 1}

EXPLANATION OF FIGURES

Photomicrographs of cross sections of vaginas taken from mice which were sacrificed during the respective stages of the reproductive cycle. All are magnified $20 \times$.

1 Estrus. Note how thick, cornified epithelium arches margin and widens lumen. This firm wall presents effective resistance to inward (radial) proliferation. Mouse no. 269.

2 Diestrus. Lumen contains characteristic secretion and leueocytes; wall lacks support and symmetry; is soft and flabby. Mouse no. 336.

3 Eight days pregnant. Section somewhat larger than arerage for this stage. Note absence of secondary folds in epithelium (compare with fig. 5). Mouse no. 24.

4 Twelve days pregnant. Similar to 8-day stage. Both are typical of pseudopregnaney and early pregnancy in absence of secondary epithelial folds. Mouse no. 64 .

5 Fighteen days pregnant. Somewhat smaller than average. Note marked, secondary folds in epithelium. Extra-epithelial wall is adapted to folded mucosa with little change in perimeter, suggesting tonus. Mouse no. 36 .

6 Post partum. Delivered seren embryos 20 days after observed copulation. Sacrificed at onee thereafter. Very flabby; secondary folds relaxed; absence of tonus unarked (compare with fig. 5). Note vaseularity and tissue spaces even at low magnification. Mouse no. 396. 


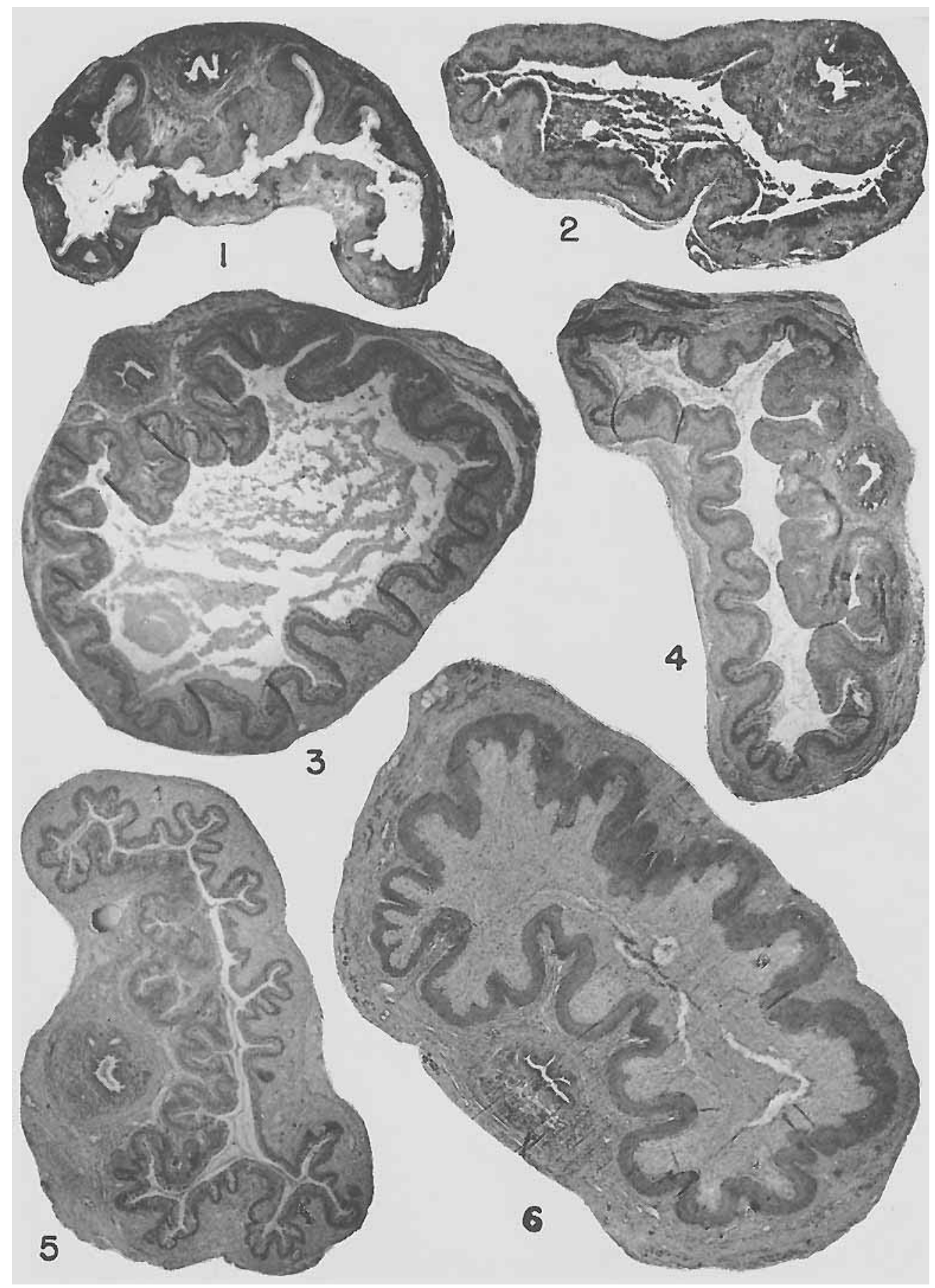


PLATE 2

WXPLANATION OF FIGURES

Photomicrographs of section detail of vaginas taken from mice which were sacrificed during respective stages of the reproductive cycle. All magnified $200 \times$.

7 Estrus. Mitotic activity beneath a heavily cornified stratum corneum is common at this stage. Mitosis is rare in compact, extra-epithelial tissue. Mouse no. 74 .

8 Diestrus. Secretory metaplasia is well demonstrated in the marginal epithelial cells. Compare mucification here with that in figure 10. Extra-epithelial tissues also compact here. Mouse no. 336 .

9 Four days pregnant. Secretory metaplasia as seen in pseudopregnaney or early pregnancy. Mitotic figures not abundant even in epithelium. Mouse no. 375 .

10 Eight days pregnant. Mucification is well advanced here. Mitotic figures are frequent although not as numerous as later. Lamina propria and muscularis (obscure) apparently somewhat loosened. Mouse no. 24.

11 Twelve days pregnant. Epithelium no thicker than earlier. Extra-epithelial layers somewhat more loosened. Mouse no. 64 .

12 Eighteen days pregnant. Epithelium still no thicker than earlier due to lateral proliferation (note mitotic figures). Lamina propria and muscularis obviously loosened; adventitia compact. Mouse no. 36. 
R. DHAN SCHICK
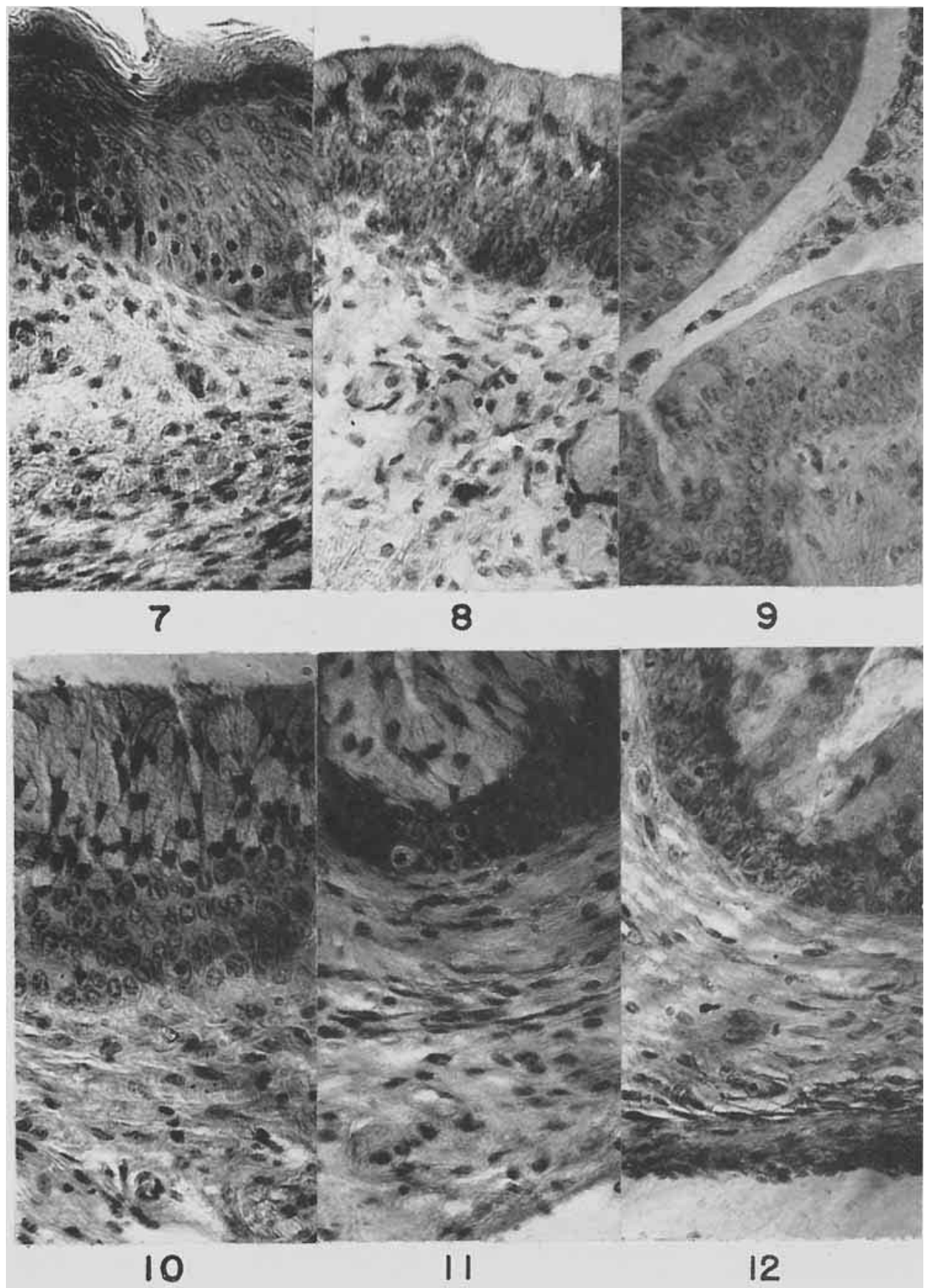